FROM THE NATIONAL CENTER FOR HEALTH STATISTICS

\title{
Gestational Weight Gain* Among Women with Full-Term, Singleton Births, Compared with Recommendations - 48 States and the District of Columbia, 2015
}

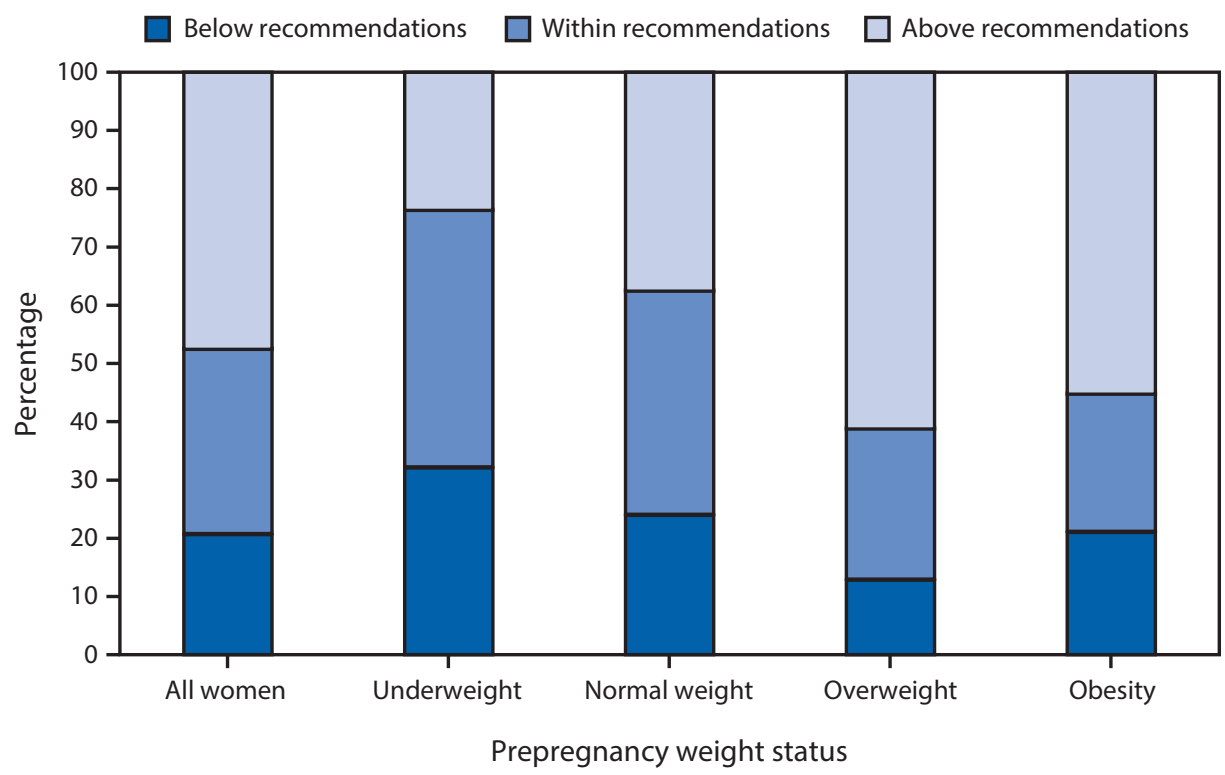

* Institute of Medicine recommendations are based on prepregnancy body mass index (BMI): 28-40 pounds for underweight women $(\mathrm{BMI}<18.5), 25-35$ pounds for normal weight women $(\mathrm{BMI}=18.5-24.9), 15-25$ pounds for overweight women (BMI $=25.0-29.9)$, and 11-20 pounds for women with obesity (BMI $\geq 30.0)$.

\begin{abstract}
Gestational weight gain was within the recommended range for $32 \%$ of women giving birth to full-term, singleton infants in 2015, with $48 \%$ gaining more weight and $21 \%$ less weight than recommended. Approximately $44 \%$ of women who were underweight before pregnancy gained within the recommendations, compared with $39 \%$ of women who were normal weight, $26 \%$ of women who were overweight, and $24 \%$ of women with obesity before pregnancy. Weight gain above the recommendations was highest among women who were overweight (61\%) or had obesity (55\%) before pregnancy.
\end{abstract}

Source: National Vital Statistics System birth data. http://www.cdc.gov/nchs/nvss/births.htm.

Reported by: Amy M. Branum, PhD, ambranum@cdc.gov, 301-458-4731; Andrea J. Sharma, PhD; Nicholas P. Deputy, MPH. 